\title{
The Respiratory Response of Healthy Term Infants to Breath-by-Breath Alternations in Inspired Oxygen at Two Postnatal Ages
}

\author{
NICOLE A. CALDER, BRIDGET A. WILLIAMS, PREM KUMAR, AND MARK A. HANSON \\ The Fetal and Neonatal Research Group, Department of Obstetrics and Gynaecology, University. College Medical \\ School, University College London, London $\mathrm{H}^{\prime} \mathrm{ClE}$ 6HX. United Kingdom /N.A.C., B.A.H.. W.A.H.J and the \\ Department of Physiology;, University of Birmingham, Birmingham B15 2TT, United Kingdom [P.K.]
}

\begin{abstract}
We have studied the reflex respiratory responses to breath-by-breath alternations in fractional inspired oxygen in a group of healthy term infants at two ages, $43 \pm 7 \mathrm{~h}$ (study 1 ) and $47 \pm 3 \mathrm{~d}$ (study 2 ). Respiration was measured noninvasively using inductance plethysmography. Responses to alternations of fractional inspired oxygen between 0.16 and 0.21 (test runs) were compared with responses to alternating the inspired gas between two lines each containing a fractional inspired oxygen concentration of 0.21 (control runs). The respiratory response was measured as the mean percentage breath-by-breath alternation for inspiratory tidal volume $\left(\mathrm{V}_{\mathrm{TI}}\right)$, expiratory tidal volume $\left(V_{T E}\right)$, inspiratory time $\left(T_{1}\right)$, expiratory time $\left(T_{E}\right)$, frequency $(f)$, mean inspiratory flow $\left(V_{T 1} / T_{1}\right)$, mean expiratory flow $\left(V_{T E} / T_{E}\right)$, timing $\left(T_{1} \cdot f\right)$, and ventilation. $A$ significant chemoreflex response was present in the infants at the time of study 1 , as shown by test runs that were significantly different from control for $T_{l}, T_{E}$, f, mean inspiratory flow, mean expiratory flow, timing, and ventilation $(p<0.05)$, and at study 2 for $V_{T l}, V_{T E}, T_{E}$, f, mean inspiratory flow, mean expiratory flow, timing, and ventilation $(p<0.05)$. When control and test runs were compared separately with respect to age, there were no significant differences for any respiratory variable between study 1 and study 2 . Thus, we did not observe significant maturation of respiratory chemoreflex responses to hypoxia after an age at which we could detect an established response, and this suggests that the "resetting" of chemoreceptor responses to hypoxia is essentially complete within approximately $24-48 \mathrm{~h}$ of birth in humans. (Pediatr Res 35: 321-324, 1994)
\end{abstract}

\section{Abbreviations}

$\mathrm{FIO}_{2}$, fractional inspired oxygen concentration

$\mathrm{V}_{\mathrm{Tl}}$, inspiratory tidal volume

$V_{\text {TF }}$, expiratory tidal volume

$T_{I}$, inspiratory time

$T_{F}$, expiratory time

f, frequency

$V_{E}$, ventilation

SIDS, sudden infant death syndrome

Received May 18, 1993; accepted October 28, 1993.

Correspondence: Nicole Calder, Department of Obstetrics and Gynaecology, University College and Middlesex School of Medicine, University College London 86-96 Chenies Mews, London WC1E 6HX.

Supported by the Foundation for the Study of Infant Deaths and the Wellcome Trust.
Direct evidence for the process of chemoreceptor "resetting" has been obtained in two species. Blanco $c t$ al. (1) showed in the fetal lamb that the arterial chemoreceptors are active in utero but virtually silenced when arterial $\mathrm{PO}_{2}$ rises at birth. Resetting of carotid chemoreceptor hypoxia sensitivity occurs in lambs over the next 2-3 d. Similar resetting of aortic chemoreceptor hypoxic sensitivity has been observed in the lamb (2). Marchal et al. (3) recorded single carotid chemoreceptor responses to hypoxia in kittens and found that responses were lower in kittens aged less than $10 \mathrm{~d}$ than in older kittens. Moreover, the $\mathrm{PO}_{2}$ response curve of the younger kittens was displaced to the left of the older kittens' response curve.

Support for this concept of resetting of chemosensitivity to hypoxia has been gained from respiratory responses measured noninvasively in the kitten, lamb, and human infant (4). We developed a test of peripheral chemosensitivity, the alternate breath test, that allows the inspired gas to alternate between two mixtures on a breath-by-breath basis. When the chemoreflex respiratory responses to the test were measured in the kitten and lamb $(5,6)$, we found that the time course of maturation was appropriate for the resetting of peripheral chemosensitivity as determined by the direct recordings from the carotid sinus or aortic nerve $(1,2)$. We then showed in healthy newborn infants that the respiratory response to breath-by-breath changes in $\mathrm{FIO}_{2}$ similarly increased over the first 8 postnatal days (7). There was also the suggestion from this work that the most dramatic change occurred over the first postnatal day, with more subtle changes occurring up to the end of the first week. However, the extent to which maturation continued after the most prominent increase in chemoreflex sensitivity was unclear from this work, and because it was a cross-sectional study, intersubject variation may have blurred the results.

We conducted a longitudinal study of the responses of human infants to breath-by-breath alternations in $\mathrm{FIO}_{2}$ during the first few days after birth and again at approximately $7 \mathrm{wk}$ of age to ascertain whether there was any change in their peripheral chemoreflex sensitivity to hypoxia over this period.

\section{SUBJECTS AND METHODS}

Healthy newborn infants were recruited from the postnatal wards at University College Hospital, London, and The Royal Berkshire Hospital, Reading. Local ethical committee approval and written parental consent were obtained. Infants delivered either vaginally or by cesarean section were studied, inasmuch as it has been shown previously that there is no significant difference in response between the two groups (7). The initial studies were performed on the postnatal wards before mothers and babies were discharged. The study was repeated in the antenatal clinic when mothers and babies returned for their 6wk postnatal checkup for infants delivered by cesarean section. 
For infants delivered vaginally, the study was repeated at approximately $6 \mathrm{wk}$ in a room on the labor ward.

The infants were settled after being fed, and recording began when they were in quiet sleep as judged behaviorally (8). Ambient temperature ranged between $23^{\circ}$ and $28^{\circ} \mathrm{C}$ on the postnatal wards and $23^{\circ}$ and $25^{\circ} \mathrm{C}$ when the studies were repeated. Infants were wearing a one-piece towelling outfit at the time of study and were covered with a single blanket. They were studied in the lateral or supine position (7). Breathing was measured by inductance plethysmography (Respitrace Corp., Ardsley, NY) calibrated by the method of Sackner et al. (9) to derive scaling factors for the ribcage and abdominal signals, the Respitrace being adjusted accordingly. The "tidal volume" signal derived by summation of the ribcage and abdominal signals was passed online to a BBC Master 128 Acorn microcomputer (British Broadcasting Corp., Cambridge, UK) and digitized at $100 \mathrm{~Hz}$ for offline analysis. Inspired gas was humidified and supplied to the infant at a rate in excess of minute ventilation, i.e. at $2.0-2.5 \mathrm{~L} /$ min, via a nasal catheter (no. 1615, Salter Labs, Arvin, CA) attached via a Y-connector to two gas delivery lines. The composition of gas in each delivery line was set using rotameters connected to cylinders of medical grade air $\left(\mathrm{FIO}_{2} \mathrm{0.21}^{2}\right)$ and gas with an $\mathrm{FIO}_{2}$ of 0.16 and the balance $\mathrm{N}_{2}$ (precalibrated; British Oxygen Company special gases). Delivery of inspired gas through a pair of three-way solenoid-operated valves was controlled by the computer, which switched between them at the start of each expiration. During test runs, breath-by-breath alternations of air and an $\mathrm{FIO}_{2}$ of 0.16 were delivered for up to 100 breaths. During control runs, air was delivered in both gas delivery lines. A minimum of two test and two control runs was necessary for the data to be included in the analysis. Oxygen saturation was monitored throughout the procedure by a pulse oximeter operating in the beat-to-beat mode (Nellcor N200, Nellcor Inc., Hayward, CA). Saturation was not recorded but was used as a visual safety check. It never fell below $92 \%$.

Data analysis. Data was analyzed as previously described by Williams et al. (7). For each breath, the tidal volume $\left(\mathrm{V}_{\mathrm{r}}\right.$ and $\left.V_{T E}\right)$, inspiratory time $\left(T_{I}, s\right)$, and expiratory time $\left(T_{E}, s\right)$ were found and from these were calculated respiratory frequency $[\mathrm{f}=$ $60 /\left(\mathrm{T}_{\mathrm{I}}+\mathrm{T}_{\mathrm{E}}\right)$, breaths/min], mean inspiratory flow $\left(\mathrm{V}_{\mathrm{T} 1} / \mathrm{T}_{\mathrm{I}}\right)$, mean expiratory flow $\left(V_{T E} / T_{E}\right)$, respiratory iming $\left[T_{1} /\left(T_{1}+T_{E}\right)\right]$, and ventilation $\left(V_{E}=\right.$ tidal volume.f). For each respiratory variable, the percentage alternation (i.e. the difference between a pair of consecutive breaths expressed as a percentage of the mean of the two breaths) was plotted cumulatively with respect to breath number, reversing the sign $(+$ or - ) for every second difference, so that a regular alternation produced a consistent deviation from the baseline. A slope was fitted to the line by regression analysis, the magnitude of which indicated the mean breath-by-breath percentage alternation. The absolute values of the slopes for control and test runs were compared separately between age groups and analyzed by using a Wilcoxon rank sum test. Test runs were also compared with control runs within each of the study age groups with a Wilcoxon rank sum test, using the absolute values of the slopes. In addition, test runs were compared with control runs taking into consideration the sign of the slope. Positive and negative slopes were analyzed separately, and test runs were compared with control runs by paired $t$ test. Values were considered significant when $p$ was $<0.05$.

Each infant had the responses from either two or three control and test runs analyzed. These responses were not averaged for each infant because a particular run may exhibit a stronger response for one variable than in a previous run, and inasmuch as each variable was analyzed separately, we did not wish to reduce the variation within each infant.

\section{RESULTS}

A total of 33 infants were studied in the first few postnatal days of life. Of these, only 13 repeat studies were completed successfully. The most common reason for failure was the ina- bility to achieve a quiet sleep state in these infants. In addition, some infants were excluded from analysis if the minimum of two test and two control runs were not recorded, and some mothers failed to keep their appointments for repeat studies.

Patient data are given in Table 1 . The mean postnatal age of the infants for study 1 was $43 \pm 7 \mathrm{~h}$ and for study 2 it was $47 \pm$ $3 \mathrm{~d}$. Mean values of $T_{1}, T_{E}, f$, and timing during control and test runs are given in Table 2 . No significant differences were found in these variables between control and test runs, at either age, or between ages for either control or test runs. There was a small increase in $T_{1}$ and $T_{E}$ and a small decrease in $f$ with age for control runs, although this was not significant.

The mean percentage alternations for control and test runs for the two age groups are shown in Figure 1. When control runs were compared with test runs within each age group, all variables exhibited test responses significantly different from control, with the exception of $V_{T I}$ and $V_{T E}$ for study 1 and $T_{I}$ for study 2 . However, when analysis took into account the sign of the slope, and positive and negative values were considered separately, test responses were significantly greater than control for positive values of $\mathrm{V}_{\mathrm{TI}}$ and negative values of $\mathrm{V}_{\mathrm{TE}}$ for study 1 . This method of analysis did not detect a significant difference between test and control for $T_{1}$ for study 2 . These findings were consistent with previous results.

When control and test runs were compared separately between the two age groups, no significant difference was detected for any of the respiratory variables.

\section{DISCUSSION}

The alternate breath test provides a measure of respiratory peripheral chemoreflex sensitivity. We have previously shown that section of the carotid sinus nerves in newborn lambs within $36 \mathrm{~h}$ of birth abolished the response to the test measured when they were 5-6 d old, and the response was still greatly reduced at 10-11 d compared with sham-operated lambs (6). This shows that the carotid chemoreceptors are foremost in producing the

Table 1. Patient information

\begin{tabular}{cccccc}
\hline & & & & & Birth \\
No. & Sex & $\begin{array}{c}\text { Study 1 } \\
\text { (h) }\end{array}$ & $\begin{array}{c}\text { Study 2 } \\
\text { (d) }\end{array}$ & $\begin{array}{c}\text { Gestation } \\
\text { (wk) }\end{array}$ & $\begin{array}{c}\text { weight } \\
\text { (g) }\end{array}$ \\
\hline 1 & F & 72 & 31 & 38 & 3140 \\
2 & M & 24 & 62 & 38 & 2900 \\
3 & M & 48 & 65 & 39 & 3060 \\
4 & F & 27 & 43 & 37 & 3520 \\
5 & M & 32 & 43 & 38 & 3100 \\
6 & M & 54 & 44 & 38 & 3780 \\
7 & F & 40 & 59 & 40 & 2600 \\
8 & M & 70 & 48 & 42 & 3860 \\
9 & F & 15 & 51 & 42 & 3720 \\
10 & M & 96 & 44 & 38 & 3140 \\
11 & F & 32 & 54 & 42 & 3220 \\
12 & F & 17 & 20 & 42 & 3420 \\
13 & M & 26 & 42 & 42 & 4340 \\
Mean \pm & & $43 \pm 7$ & $47 \pm 3$ & $40 \pm 1$ & $3369 \pm 129$ \\
SEM & & & & & \\
\hline
\end{tabular}

Table 2. Baseline values for respiratory variables (mean + SEM)

\begin{tabular}{lcccc}
\hline & $\begin{array}{c}\text { Inspiratory } \\
\text { time }(\mathrm{s})\end{array}$ & $\begin{array}{c}\text { Expiratory } \\
\text { time }(\mathrm{s})\end{array}$ & $\begin{array}{c}\text { Frequency } \\
\text { (breaths/ } \\
\mathrm{min})\end{array}$ & $\begin{array}{c}\text { Timing } \\
\left(\mathrm{T}_{\mathrm{l}} / \text { total time }\right)\end{array}$ \\
\hline $\begin{array}{c}\text { Study 1 } \\
\text { Control }\end{array}$ & $0.50 \pm 0.02$ & $0.77 \pm 0.06$ & $52.0 \pm 3.0$ & $0.41 \pm 0.01$ \\
$\quad \begin{array}{l}\text { Test } \\
\text { Study 2 }\end{array}$ & $0.52 \pm 0.02$ & $0.83 \pm 0.07$ & $49.8 \pm 3.0$ & $0.41 \pm 0.01$ \\
Control & $0.54 \pm 0.02$ & $0.79 \pm 0.04$ & $48.0 \pm 2.4$ & $0.42 \pm 0.01$ \\
Test & $0.53 \pm 0.02$ & $0.75 \pm 0.03$ & $49.2 \pm 1.8$ & $0.42 \pm 0.01$ \\
\hline
\end{tabular}


A.

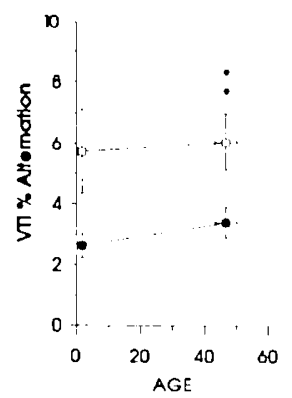

D.

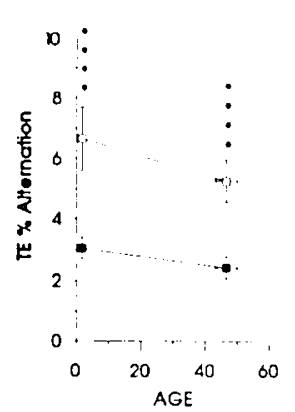

G.
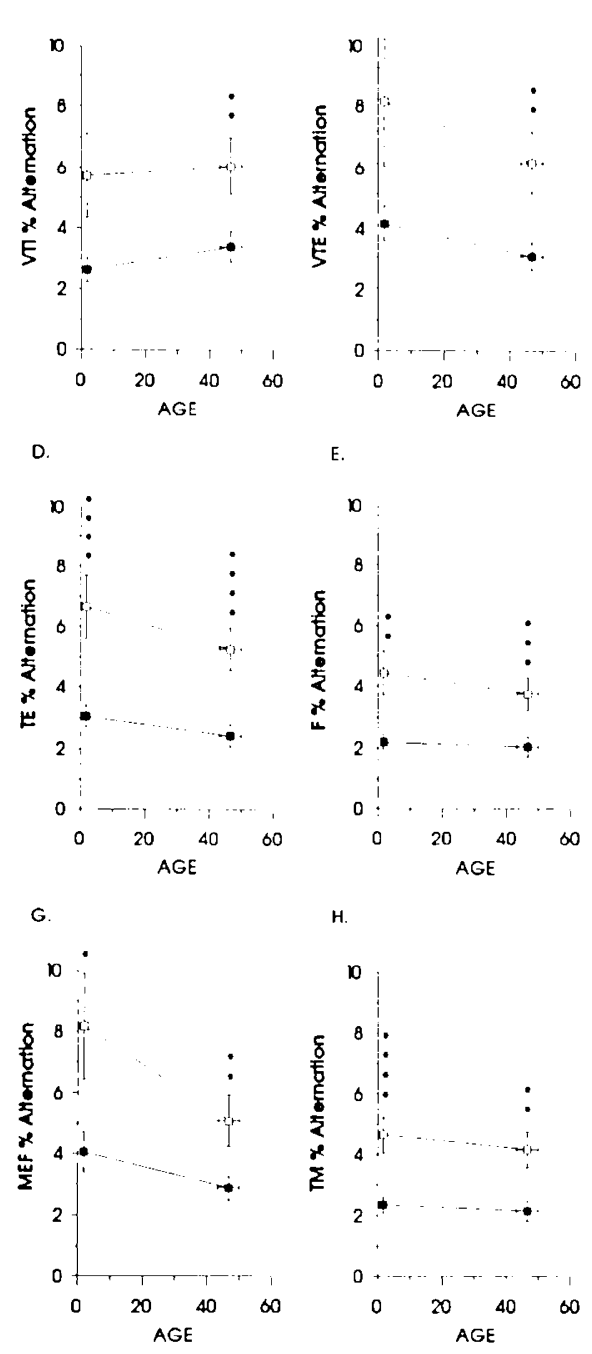

E.
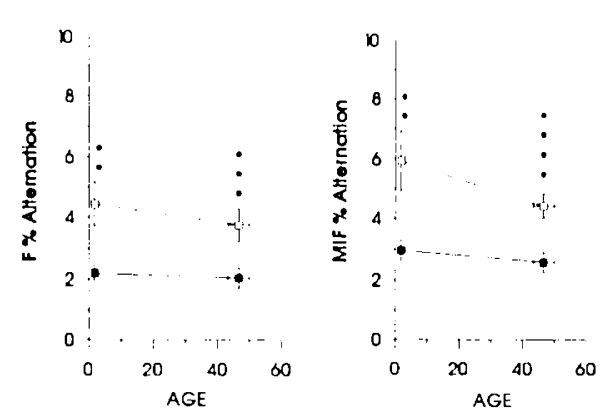

।.

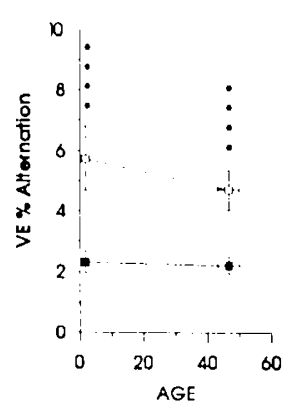

Fig. 1. Mean percentage breath-by-breath alternation between $\mathrm{FIO}_{2}$ 0.21 and 0.21 (control), or 0.21 and 0.16 (test) at two separate postnatal ages. Filled squares are control runs and open squares are test runs. $A$, $\mathrm{V}_{\mathrm{TI}} ; B, \mathrm{~V}_{\mathrm{TE}} ; C, \mathrm{~T}_{1} ; D, \mathrm{~T}_{\mathrm{E}} ; E, \mathrm{f} ; F, \mathrm{MIF}$, mean inspiratory flow; $G, \mathrm{MEF}$ mean expiratory flow; $H$, TM, timing; $I, \mathrm{~V}_{\mathrm{E}}$. Asterisks show significant differences between control and test runs: ${ }^{*}, p<0.05 ;{ }^{* *}, p<0.025 ;{ }^{* * *}$, $p<0.01$; and ${ }^{* * *}, p<0.005$ by Wilcoxon rank sum test.

response. Moreover, the test detects the postnatal maturation of respiratory chemoreflexes in the kitten and lamb, species in which the neonatal increase in chemoreceptor hypoxia sensitivity has been established by direct recordings (1-3).

Our present results show that the response of the newborn infant to alternate breaths of air and a hypoxic gas remains unchanged from approximately $48 \mathrm{~h}$ to approximately $7 \mathrm{wk}$ of age. The response for study 1 is appropriate for the 24- to 48-h age group as measured by Williams $e t$ al. (7). In their crosssectional study, the resetting of hypoxic chemosensitivity that had occurred between the 3- to 10-h and 24- to 48-h age groups was evident from the tidal volume, mean inspiratory flow, and $\mathrm{V}_{\mathrm{E}}$ responses. Although the number of variables responding was greater in the babies aged 3-4 d and 5-8 d, and the magnitude of the test responses also increased further, this cannot be taken as firm evidence for a graded maturation of chemosensitivity over this period in a given infant because it was not a longitudinal study. Thus, individual variation between infants may have influenced the results. To investigate specifically the question of whether changes in hypoxic chemosensitivity do occur once the respiratory chemoreflex response has been established, we studied a group of infants at two ages. We did not see a significant difference in the magnitude of the control or test response between ages, which supports the idea that there is no additional maturation of respiratory chemoreflexes after resetting has occurred. Thus, it appears that resetting of chemoreceptor sensitivity occurs more rapidly in humans than in the lamb and kitten, in which it appears to occur slowly over a few days.

We have used the alternate breath test to measure hypoxic peripheral chemosensitivity in infants because of the advantage of repeating the stimulus over a number of breaths, which allows the response to be averaged. The ventilatory response to hyperoxia has also been used as a test of peripheral chemosensitivity, particularly the Dejours test (10), which substitutes a single breath of $100 \% \mathrm{O}_{2}$ for air during quiet breathing. The response to such transient hyperoxia is variable, and there is no way of identifying the breath responding to the stimulus, making analysis complex. However, results obtained by this method broadly agree with ours. Hertzberg and Lagercrantz (11) used a variation of the Dejours technique and found in term infants that the decrease in $\mathrm{V}_{E}$ to $30 \mathrm{~s}$ of $100 \% \mathrm{O}_{2}$ at 2-6 d was more than that at $2-6 \mathrm{~h}$ after birth. Then, in a longitudinal study using the Dejours test, Parks et al. (12) reported that the response of infants aged 1, 2, and 3 mo was not significantly different. Although the youngest age group of this study was closer in age to our older age group, it is evident that any maturational changes of hypoxic chemosensitivity have occurred before 1 mo of age.

Poor respiratory control is postulated to be a cause of SIDS. Because peripheral chemoreceptors are predominant in initiating the ventilatory, cardiovascular, and arousal responses to hypoxia or asphyxia, it can be postulated that victims of SIDS had an absent or inadequate input from the peripheral chemoreceptors, and there is evidence for abnormalities of carotid body function in victims of SIDS (13-15). Delayed resetting of peripheral chemosensitivity to hypoxia as reported in chronically hypoxic kittens (5) will prevent an adequate response to acute hypoxia. Alternatively, it may be that SIDS victims were unable to produce an adequate response to an increased chemoreceptor discharge. Elevated environmental temperatures and prone sleeping position, both of which are associated with an increased incidence of SIDS (16), may be involved in such a reduction in the gain of respiratory chemoreflexes, and there is evidence in kittens for a reduced chemoreflex response to hypoxia and $\mathrm{CO}_{2}$ at warmer temperatures (17).

In summary, we have shown that in healthy newborns there is no additional maturation of respiratory chemoreflexes evident between the first week and the second month of postnatal life. Current evidence suggests that chemoreflex failure may be implicated in victims of SIDS. However, we do not know at present whether this is caused by perturbation of the rapid resetting of hypoxic chemosensitivity we have observed in this study, because other factors may be responsible for reducing the gain of respiratory chemoreflexes in SIDS victims.

\section{REFERENCES}

1. Blanco CE, Dawes GS, Hanson MA. McCooke HB 1984 The response to hypoxia of arterial chemoreceptors in fetal sheep and new-born lambs. $J$ Physiol (Lond) 351:25-37

2. Kumar P, Hanson MA 1989 Re-setting of the hypoxic sensitivity of aortic chemoreceptors in the newborn lamb. J Dev Physiol 11:199-206

3. Marchal F, Bairam A, Haouzi P, Crance JP, Di Giulio C, Vert P, Lahiri S 1992 Carotid chemoreceptor response to natural stimuli in the newborn kitten. Respir Physiol 87:183-193

4. Hanson MA 1986 Peripheral chemoreceptor function before and after birth. In: Johnston BM, Gluckman PD (eds) Respiratory Control and Lung Development in the Fetus and Newborn. Perinatology Press, New York, pp $311-330$

5. Hanson MA. Kumar P, Williams BA 1989 The effect of chronic hypoxia upon the development of respiratory chemoreflexes in the newborn kitten. J Physiol (Lond) 411:563-574

6. Williams BA, Hanson MA 1990 Role of the carotid chemoreceptors in the respiratory response of newborn lambs to alternate pairs of breaths of air and a hypoxic gas. J Dev Physiol 13:157-164

7. Williams BA, Smyth J, Boon AW, Hanson MA, Kumar P, Blanco CE 1991 Development of respiratory chemoreflexes in response to alternations of 
fractional inspired oxygen in the newborn infant. J Physiol (Lond) 442: $81-90$

8. Prechtl HFR 1974 The behavioural states of the newborn infant (a review). Brain Res 76:185-212

9. Sackner MA, Watson H, Belsito AS. Feinerman D. Suarez M. Gonzalez G, Bizousky F, Krieger B 1989 Calibration of respiratory inductive plethysmograph during natural breathing. J Appl Physiol 66:410-420

10. Girard F. Lacaisse A. Dejours $P 1960$ Le stimulus $\mathrm{O}_{2}$ ventilatoire à la periode neonatale chez l'Homme. J Physiol (Paris) 52:108-109

11. Hertzberg T, Lagercrantz H 1987 Postnatal sensitivity of the peripheral chemoreceptors in newborn infants. Arch Dis Child 62:1238-1241

12. Parks YA, Beardsmore CS, MacFayden UM, Pallot DJ, Goodenough PC Carpenter R. Simpson H 1991 The effect of a single breath of $100 \%$ oxygen on breathing in infants at 1,2 and 3 months of age. Am Rev Respir Dis
144:141-145

13. Naeye RL, Fisher R, Ryser M, Whalden P 1976 Carotid body in the sudden infant death syndrome. Science 191:567-569

14. Pallot DJ 1987 Carotid body pathology. In: The Mammalian Carotid Body. Springer-Verlag. Berlin, pp 50-68

15. Perrin DG, Cutz E, Becker LE, Bryan AC, Madapallimatum A. Sole MJ 1984 SIDS: increased carotid-body dopamine and noradrenaline content. Lancet 2:535-537

16. Fleming PJ, Gilbert R, Azaz Y, Berry PJ, Rudd PT, Stewart A, Hall A 1990 Interaction between bedding and sleeping position in the sudden infant death syndrome: a population based case-control study. Br Med J 301:85-89

17. Watanabe T, Kumar P, Hanson MA 1993 Effect of warm environmental temperature on the gain of the respiratory chemoreflex in the kitten. J Physiol (Lond) 459:336P(abstr)

\section{Announcement}

The Stable Isotopes in Nutritional and Metabolic Research 2nd World Conference will be held July 7-8, 1994 at the Erasmus Expo and Conference Centre, Erasmus University Rotterdam, The Netherlands. For further information, please contact: Erasmus Forum, Erasmus University Rotterdam, P.O. Box 1738, NL-3000 DR Rotterdam, phone $+31.10 .408 .23 .02 / 10.98$, fax +31.10 .453 .07 .84 . 